\title{
The Risk and Related Factors for Readmission to an ICU Within 7 Days in Mechanically Ventilated Subjects-A Nationwide Population-Based Cohort Study
}

\author{
Chia-Chen Chu RRT FAARC, Chin-Jung Liu RRT, Chuen-Ming Shih MD, Pei-Tseng Kung ScD, \\ Yuh-Show Tsai PhD, and Wen-Chen Tsai DrPH
}

\begin{abstract}
BACKGROUND: Readmission of mechanically ventilated patients to an ICU within $7 \mathrm{~d}$ reflects not only patient safety but also the quality of care of the ICU. This study aimed to investigate the risk and related factors for readmission to an ICU within $7 \mathrm{~d}$ in mechanically ventilated subjects. METHODS: A total of 658,452 mechanically ventilated subjects discharged from an ICU whose age was $\geq 17$ y old were obtained from the Taiwan National Health Insurance Research Database for the period from January 1, 2005, to December 31, 2011. The study applied a generalized estimating equation logistic regression model to explore whether the mechanically ventilated subjects were readmitted within $7 \mathrm{~d}$ or not and the related factors. RESULTS: A total of 29,657 subjects were readmitted to the ICU within $7 \mathrm{~d}$; the total readmission rate was $4.5 \%$. Also, $64.8 \%$ of the subjects with the same diagnosis were returned to the ICU within $7 \mathrm{~d}$. Generalized estimating equation logistic regression model results showed that the factors related to higher risk of readmission were male sex, old age, higher comorbidity score, complications (eg, pneumothorax, subcutaneous emphysema, pneumonia, oxygen toxicity, pulmonary embolism, or pulmonary edema), use of a private hospital ICU, ICU stay $\geq 21 \mathrm{~d}$, transfer to a respiratory care center and respiratory care ward, and subsequent transfer to the regional hospital or district hospital. CONCLUSIONS: The risk and related factors of a mechanically ventilated subject whose age is $\geq 17 \mathrm{y}$ old being readmitted to the ICU within $7 \mathrm{~d}$ include subject characteristics, health status, hospital attributes, and the length of ICU stay. Therefore, higher risk subjects should receive attention and assessment before transfer or discharge from the ICU to prevent readmission. Key words: mechanically ventilated subjects; intensive care unit (ICU); ICU readmission; respiratory care center; respiratory care ward. [Respir Care 2015;60(12):1786-1795. ( 2015 Daedalus Enterprises]
\end{abstract}

\section{Introduction}

In 1953, anesthesiologist Bjørn Ibsen established the world's first ICU in Copenhagen and admitted patients

\footnotetext{
Mr Chu, Mr Liu, and Dr Shih are affiliated with the Department of Respiratory Therapy, and Dr W-C Tsai is affiliated with the Department of Health Services Administration, China Medical University, Taichung, Taiwan. Mr Chu and Mr Liu are also affiliated with the Department of Respiratory Therapy, and Dr Shih is affiliated with the Division of Pulmonary and Critical Care Medicine, China Medical University Hospital, Taichung, Taiwan. Mr Chu and Dr Y-S Tsai are affiliated with the Department of Biomedical Engineering, Chung-Yuan Christian University, Jhongli, Taiwan. Dr Kung is affiliated with the Department of Healthcare Administration, Asia University, Taichung, Taiwan.
}

who were diagnosed with respiratory failure and required ventilators to facilitate breathing for intensive care. ${ }^{1,2}$ Since 1979, United States federal and state policies have demanded that hospitals holding $>500$ beds establish ICUs. Thus, the number of intensive care beds began to increase and reached 94,000 in 2005, and high-quality care in-

\footnotetext{
Mr Chu presented a version of this paper at the American Association for Respiratory Care Congress 2014, held December 9-12, 2014, in Las Vegas, Nevada.

The first 2 authors contributed equally to this work.

Supplementary material related to this paper is available at http://www. rcjournal.com.
} 
creased subjects' stay in the ICU as well as associated costs. $^{3-5}$ In 1985, the step-down care model (Vencor, Louisville, Kentucky) was developed in the United States to relieve ICUs that were overcrowded with ventilator-dependent patients.

Since the National Health Insurance of the Republic of China was implemented in 1995, ventilator use has been covered, and patients' families need not bear excessive costs. Consequently, ICUs have become overcrowded with patients on ventilators. To solve this problem, the Ministry of Health and Welfare (Republic of China) organized a group visit to Vencor Hospital in 1996 and commenced the Improved Emergency and Critical Care Plan in 1997, during which the National Health Insurance Administration, Ministry of Health and Welfare, formulated the National Health Insurance Managed Care Prospective Payment System Demonstration Program for VentilatorDependent Patients. This program established a 4-stage step-down care model for ventilator-dependent patients (age $17 \mathrm{y}$ and older). The 4 stages comprised the duration of stays at the ICU, respiratory care center, and respiratory care ward and home respiratory care. The maximum stay in the ICU is $21 \mathrm{~d}$, and vertical and horizontal services were enhanced at medical institutions. The authorities used this method to increase the weaning success of stable ventilator-dependent patients from the ICU at the respiratory care centers. Patients who failed to wean from their ventilators were transferred to step-down respiratory care wards and home respiratory care to alleviate the lack of ICU beds. ${ }^{6,7}$ However, both American and Taiwanese studies have shown that the redistribution of hospital locations for long-term ventilator-dependent subjects reduced the occupancies of ICU beds and increased ventilator weaning success rates but still increased the overall stay and medical costs of hospitals. ${ }^{8-10}$

Previous studies on ICU readmission have focused on all patients in the investigated ICU. Although ventilator-dependent subjects have been studied, tracking times for ICU readmissions were comparatively lengthy. By investigating the

\footnotetext{
This study is based in part on data from the Taiwan National Health Insurance Research Database provided by the National Health Insurance Administration, Ministry of Health and Welfare and managed by National Health Research Institutes. The interpretation and conclusions contained herein do not represent those of the National Health Insurance Administration, Ministry of Health and Welfare, or National Health Research Institutes. This study was supported by China Medical University Hospital Grant DMR-103-009 and Taiwan Department of Health Clinical Trial and Research Center of Excellence Grant DOH101-TD-B-111-004. The authors have disclosed no conflicts of interest.
}

Correspondence: Wen-Chen Tsai DrPH, China Medical University, 91 HsuehShih Road, 40402 Taichung, Taiwan. E-mail: wtsai@mail.cmu.edu.tw.

DOI: $10.4187 /$ respcare. 03868

\section{QUICK LOOK}

\section{Current knowledge}

Readmission to the ICU is often used as a measure of ICU quality and patient safety. Readmission to the ICU is associated with prolonged mechanical ventilation and greater mortality. The factors leading to ICU readmission from a step-down unit have not been well described.

\section{What this paper contributes to our knowledge}

Readmission of mechanically ventilated subjects within $7 \mathrm{~d}$ of discharge was associated with greater costs and worse outcomes. Age, male sex, an ICU stay of $>3$ weeks, and discharge on mechanical ventilation to a weaning unit were all risk factors for readmission. These factors might be used to determine optimal time for ICU discharge and to prevent readmission through early intervention.

risks and relevant factors associated with mechanical ventilation subjects readmitted within $7 \mathrm{~d}$ of ICU step-down, the results can provide a reference to relevant health administrative authorities for establishing policies on caring for mechanical ventilation patients.

\section{Methods}

\section{Research Subjects and Data Sources}

This is a retrospective cohort study that utilized the National Health Insurance Research Database published by the National Health Research Institutes (Republic of China) for obtaining mechanical ventilation subjects age $17 \mathrm{y}$ and older from ICU step-down transfers between January 1, 2005 and December 31, 2011. The primary diagnoses for each step-down transfer and readmission were recorded using the International Classification of Diseases, 9th Revision, Clinical Modification codes. Ventilated subjects included those using invasive and noninvasive ventilation. The subjects using noninvasive ventilation had to have switched from invasive ventilation because of improved conditions.

\section{Variable Definitions and Descriptions}

This study investigated the risks and relevant factors regarding whether mechanical ventilation subjects are readmitted within $7 \mathrm{~d}$ after ICU step-down. The relevant variables comprised subject demographics (ie, sex, age, monthly salary, and the degree of urbanization of the res- 
idence area), health status (including comorbidity severity and complications of the subjects), ICU hospital characteristics (including the level and ownership of the hospital), extended-care facility properties (including hospital ownership and the type of extended-care facility), and stay (days) in the ICU.

Regarding age, the criteria were those specified in the National Health Insurance Managed Care Prospective Payment System Demonstration Program for Ventilator-Dependent Subjects. The age groups were 17-44, 45-54, $55-64,65-74$, and $\geq 75 \mathrm{y}$. Regarding monthly salary, this study divided the subjects according to the following income groups: low-income households $\leq$ New Taiwan Dol$\operatorname{lar}(\mathrm{NT}) \$ 17,880$, NT $\$ 17,881-22,800, \mathrm{NT} \$ 22,801-28,800$, NT\$28,801-36,300, NT\$36,301-45,800, NT\$45,80157,800 , and high-income households $>$ NT $\$ 57,800$. The definition of low-income household was based on the criteria of government regulations. Furthermore, this study adopted stratified analysis to distinguish the degree of urbanization of the subjects' residence areas into 7 clusters based on the degree of urbanization of townships in Taiwan. ${ }^{11}$ According to the 7 clusters, since some areas had few subjects, we then divided the degrees of urbanization of the residence areas into 4 groups (ie, Levels 1, 2, 3-4, and 5-7). High levels denote low degrees of urbanization.

In addition, this study used the Charlson comorbidity index to measure the severity of the subjects' comorbidities. ${ }^{12}$ The Charlson comorbidity index scores were $0,1,2$, $3-4$, and $\geq 5$. High scores indicate high comorbidity severities. Regarding subject complications during hospitalization, we grouped the subjects into the 7 complication types of laryngeal edema, pneumothorax, subcutaneous emphysema, pneumonia, oxygen toxicity, pulmonary embolism, and pulmonary edema.

The ICU hospital levels comprised medical centers, regional hospitals, and district hospitals, and the hospitals were public and private. The ICU hospitals were the hospitals at which the subjects stayed during their time in the ICU, whereas the extended-care hospitals were the hospitals at which the subjects stayed following ICU step-down. In addition, these hospitals comprised public and private hospitals providing the following 4 institution types: general ward, respiratory care center, respiratory care ward, and home respiratory care.

Regarding the stay in the ICU, this study adhered to the staged-care requirements specified by the National Health Insurance Managed Care Prospective Payment System Demonstration Program for Ventilator-Dependent Patients and divided the subjects into groups with ICU residency less than, equal to, and more than $21 \mathrm{~d}$. In addition, we calculated the subjects' stay (days) in the ICU before the current ICU step-down.

\section{Statistical Analysis}

This study applied the SAS 9.3 software suite for database processing and statistical analysis, used frequency distributions and percentages for describing various variable distributions, and employed means and SD values for presenting the distributions of continuous variables. We further adopted the chi-square test to determine whether significant differences existed in demographics, health status, hospital characteristics, type of extended-care facility, and stay in the ICU of subjects who were and were not readmitted to the ICU within $7 \mathrm{~d}$ after step-down.

The subjects of this study were readmitted to the ICU within $7 \mathrm{~d}$ after step-down. Thus, each observed value represents one residency record at the ICU for the subjects on ventilators. These subjects might be repeatedly observed. In order to resolve the influence of the subjects who had $>1$ time of readmission to the ICU within $7 \mathrm{~d}$ after stepdown, the generalized estimating equation approach could be used in the analysis. Therefore, this study performed logistic regression analysis using a generalized estimating equation to investigate the key factors determining whether mechanical ventilation subjects were readmitted to the ICU within $7 \mathrm{~d}$ after step-down. This study was approved by the Institutional Review Board of the study organizations (number 20130603C).

\section{Results}

\section{Subject Demographics}

From January 1, 2005, to December 31, 2011, 658,452 subjects on ventilators from the ICU who were $17 \mathrm{y}$ or older were stepped down. These subjects consisted predominantly of men (62.9\% males and $37.1 \%$ females), and the average age of the males was slightly younger than that of the females $(65.7 \pm 17.2 \mathrm{y}$ vs $69.1 \pm 16.6 \mathrm{y})$. Within $7 \mathrm{~d}$ of step-down, 29,657 subjects were readmitted (4.5\%). These subjects comprised more men than women (64.6\% vs $35.4 \%$ ), and the average age of the males was younger than that of the females $(72.6 \pm 14.5 \mathrm{y}$ vs $74.2 \pm 13.9 \mathrm{y})$. The rate of readmission of the male subjects $(4.62 \%$; $19,152 / 414,211)$ was slightly higher than that of the female subjects $(4.3 \%$; 10,505/244,244) (Table 1$)$.

The top 3 of the 5 foremost primary diagnostic codes of the stepped down subjects and readmitted subjects were acute respiratory failure, pneumonia (organism unspecified), and unspecified septicemia (11.12, 8.19, and 3.47\%, respectively, for the stepped down subjects and 25.46, 14.21 , and $7.04 \%$, respectively, for the readmitted subjects; Table 1). Regarding primary diagnoses of the readmitted subjects before and after readmissions, the rates of consistency for the subjects who stayed less than, equal to, and more than $21 \mathrm{~d}$ were $66.23,57.93$, and $61.45 \%$, re- 
Table 1. Mean Age and Primary Diagnoses of Subjects Stepping Down to Extended-Care Facilities and Readmitted to ICU Within $7 \mathrm{~d}$

\begin{tabular}{|c|c|c|c|c|c|c|c|}
\hline \multirow{3}{*}{ Variables } & \multirow{2}{*}{\multicolumn{2}{|c|}{$\begin{array}{c}\text { Total } \\
(N=658,452)\end{array}$}} & \multicolumn{4}{|c|}{ Readmitted to the ICU Within $7 \mathrm{~d}$} & \multirow{3}{*}{$P$} \\
\hline & & & \multicolumn{2}{|c|}{$\begin{array}{c}\text { No } \\
(n=628,795)\end{array}$} & \multicolumn{2}{|c|}{$\begin{array}{c}\text { Yes } \\
(n=29,657)\end{array}$} & \\
\hline & Mean & $\mathrm{SD}$ & Mean & $\mathrm{SD}$ & Mean & $\mathrm{SD}$ & \\
\hline Age, y & 66.9 & 17.0 & 66.7 & 17.1 & 73.1 & 14.3 & $<.001$ \\
\hline Female & 69.1 & 16.6 & 68.8 & 16.7 & 74.2 & 13.9 & \\
\hline Male & 65.7 & 17.2 & 65.4 & 17.2 & 72.6 & 14.5 & \\
\hline Primary diagnosis & $n$ & $\%$ & $n$ & $\%$ & $n$ & $\%$ & \\
\hline ARF & 73,206 & 11.12 & & & 7,551 & 25.46 & \\
\hline Pneumonia* & 53,939 & 8.19 & & & 4,213 & 14.21 & \\
\hline Septicemia $\dagger$ & 22,821 & 3.47 & & & 2,088 & 7.04 & \\
\hline $\mathrm{ICH}$ & 20,574 & 3.12 & & & & & \\
\hline $\mathrm{CAD}$ & 19,404 & 2.95 & & & & & \\
\hline $\mathrm{CRF}$ & & & & & 741 & 2.50 & \\
\hline Pneumonitis $\ddagger$ & & & & & 574 & 1.94 & \\
\hline $\begin{array}{l}\text { * Pneumonia, organism } \\
\dagger \text { Unspecified septicemia } \\
\text { † Pneumonitis due to inh } \\
\text { ARF = acute respiratory } \\
\text { ICH }=\text { intracerebral hem } \\
\text { CAD = coronary atheros } \\
\text { CRF = chronic respirato }\end{array}$ & or vomitus. & & & & & & \\
\hline
\end{tabular}

Table 2. Number and Percentage of Subjects Who Had a Consistent Primary Diagnosis Before and After Their ICU readmissions

\begin{tabular}{|c|c|c|c|c|c|c|}
\hline \multirow{3}{*}{$\begin{array}{l}\text { ICU Length } \\
\text { of Stay (d) }\end{array}$} & \multirow{2}{*}{\multicolumn{2}{|c|}{$\begin{array}{c}\text { Total } \\
(N=29,657)\end{array}$}} & \multicolumn{4}{|c|}{ Readmitted with the Same Diagnosis } \\
\hline & & & \multicolumn{2}{|c|}{$\begin{array}{c}\text { Yes } \\
(n=19,208[64.77 \%])\end{array}$} & \multicolumn{2}{|c|}{$\begin{array}{c}\text { No } \\
(n=10,449[35.23 \%])\end{array}$} \\
\hline & $n$ & $\%$ & $n$ & $\%$ & $n$ & $\%$ \\
\hline$<21$ & 21,514 & 72.54 & 14,249 & 66.23 & 7,265 & 33.77 \\
\hline 21 & 1,267 & 4.27 & 734 & 57.93 & 533 & 42.07 \\
\hline$>21$ & 6,876 & 23.19 & 4,225 & 61.45 & 2,651 & 38.55 \\
\hline
\end{tabular}

spectively. In summary, $64.77 \%$ of the subjects had a consistent primary diagnosis before and after their ICU readmissions (Table 2).

\section{Types of Extended-Care Facilities}

Based on the number and proportions of stepped down subjects, the institution types were ranked as follows: general wards (90.45\%; 595,568 subjects), respiratory care centers $(7.13 \% ; 46,980$ subjects), respiratory care wards $(2.36 \% ; 15,522$ subjects), and home respiratory care (0.06\%; 382 subjects). Among the 29,657 subjects readmitted within $7 \mathrm{~d}$ following step-down, the proportions of readmitted subjects were ranked in the following order: general wards $(66.62 \% ; 19,758$ subjects $)$, respiratory care centers $(21.26 \% ; 6,304$ subjects), respiratory care wards (12.05\%; 3,575 subjects), and home respiratory care
$(0.07 \%$; 20 subjects). However, the rate of ICU readmission following step-down transfers to the aforementioned extended-care facilities were in the following order: respiratory care wards $(23.03 \%)$, respiratory care centers $(13.42 \%)$, home respiratory care $(5.24 \%)$, and general ward (3.32\%) (Fig. 1).

\section{Relevant Factors Influencing Readmission}

This study performed a chi-square test to determine whether the variables of subject demographics, health status, ICU hospital characteristics, extended-care facility characteristics, type of extended-care facility, and stay in the ICU present statistically significant correlations $(P<.05)$ with the readmission of subjects on ventilators within $7 \mathrm{~d}$ after step-down (Table 3 ). 


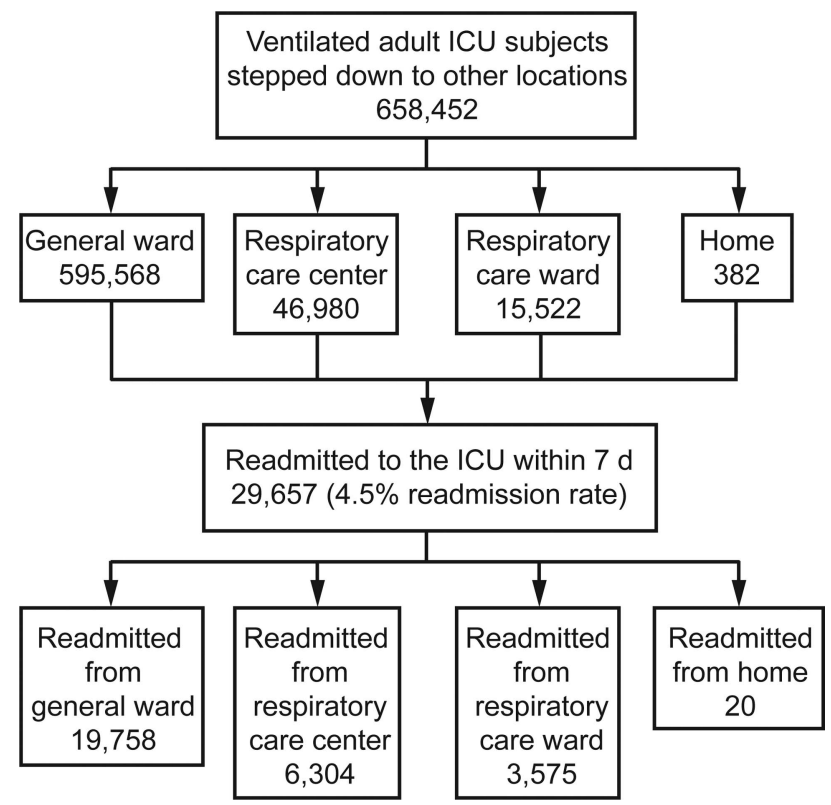

Fig. 1. Flow chart.

Regarding the sex variable, the rate of readmission for the male subjects was slightly higher than that for the female subjects $(4.62 \%$ vs $4.30 \%)$. Regarding the age variable, the rate of readmission was the highest for the $\geq 75$ y-old age group (6.29\%). The high-age groups showed increasing numbers of readmitted subjects; thus, the rate of readmission was positively correlated with age. Regarding the variable of monthly salary, the rate of readmission was the highest for the low-income household group (5.58\%), followed by the NT $\$ 22,801-28,800$ group (4.6\%). Regarding the degree of urbanization of the residence area, low degrees of urbanization yielded high rates of readmission; the Level 5-7 group exhibited the highest level (5.2\%), followed by the Level 3-4 group (4.8\%).

Regarding the severity of subjects' comorbidities (measured using the Charlson comorbidity index), the rate of readmission was the highest for the Charlson comorbidity index 3-4 group (5.33\%), which was followed by the Charlson comorbidity index $\geq 5$ group $(5.12 \%)$. Regarding complication types, the results showed that the subjects developing complications of pneumothorax, pneumonia, pulmonary edema, and oxygen toxicity exhibited significantly higher rates of readmission within $7 \mathrm{~d}$ after stepdown than did the other subjects $(P<.05)$.

Regarding ICU hospital levels (ICU hospital characteristics), district hospitals $(11.05 \%)$ displayed the highest readmission rates, followed by the regional hospitals (4.80\%). Concerning ICU hospital ownership, the rate of readmission of private hospitals was higher than that of public hospitals (4.59\% vs $4.32 \%$ ). Regarding extendedcare hospital ownership, private hospitals showed a higher rate of readmission than did public hospitals $(4.67 \%$ vs
$4.12 \%)$. Furthermore, regarding the variable of extendedcare facility type, the rate of readmission was the highest for the respiratory care wards $(23.03 \%)$, followed by the respiratory care centers $(13.42 \%)$. Finally, regarding the subjects' stay in the ICU, the top 2 rates of readmission were observed for the subjects who stayed equal to $(9.72 \%)$ and more than $(9.33 \%) 21 \mathrm{~d}$ (Table 3).

\section{Analysis of the Risks of Readmission}

Numerous subjects were repeatedly observed each year; thus, this study applied logistic regression analysis using a generalized estimating equation to investigate the risks of readmission within $7 \mathrm{~d}$ after ICU step-down. Based on stay in the ICU, as shown in Table 3, after controlling for relevant variables, the risk of readmission was the highest when the subjects stayed for $>21 \mathrm{~d}$ (odds ratio $[\mathrm{OR}]=1.51)$, followed by the subjects who stayed for exactly $21 \mathrm{~d}(\mathrm{OR}=1.19)$. Regarding age, we used the 17-44-y-old age group as a reference and determined that the risk of readmission was highest in the $\geq 75$-y-old group $(\mathrm{OR}=1.66)$, followed by the 65-74-y-old group $(\mathrm{OR}=1.51)$. Furthermore, the male subjects exhibited a risk of ICU readmission 1.16 times that of the female subjects. Concerning severity of comorbidity, the risk of readmission was the highest for the group with a Charlson comorbidity index score of $\geq 5$, which was 1.41 times that of the group with a Charlson comorbidity index score of 0 . The group with a Charlson comorbidity index score of 1 presented the lowest rate of readmission, which was 1.16 times that of the group that scored 0. Regarding monthly salaries, this study used the low-income household group as a reference, and the risks of readmission for all of the other groups $(\mathrm{OR}=0.83-0.90)$ were lower than that of the reference group. Regarding the degree of urbanization of the residence area, the Level 5-7 group showed the highest risks of readmission, 1.10 times that of the Level 1 group.

For the complications variable, the subjects without complications were used as the reference group. The risks of readmission were ranked as follows: oxygen toxicity $(\mathrm{OR}=4.85)$, pneumonia $(\mathrm{OR}=2.07)$, subcutaneous emphysema $(\mathrm{OR}=1.83)$, pneumothorax $(\mathrm{OR}=1.59)$, pulmonary edema $(\mathrm{OR}=1.26)$, and pulmonary embolism $(\mathrm{OR}=1.25)$. Regarding ICU hospital levels, the risk of readmission was the highest in the district hospitals and was 2.65 times that in the medical centers, followed by the regional hospitals, whose risks of readmission were 1.45 times those of the medical centers. Regarding hospital ownership, the risks of readmission of the private hospitals were lower than that of the public hospitals $(\mathrm{OR}=0.88)$. After post-step-down extended-care facilities were examined, the respiratory care wards exhibited the highest risk of readmission, which was 4.26 times that of the general 
Table 3. Key Factors Determining Whether Mechanical Ventilation Subjects Were Readmitted to the ICU Within 7 d After Step-down

\begin{tabular}{|c|c|c|c|c|c|c|c|c|c|c|}
\hline \multirow{3}{*}{ Variables } & \multirow{2}{*}{\multicolumn{2}{|c|}{$\begin{array}{c}\text { Total } \\
(N=658,452)\end{array}$}} & \multicolumn{4}{|c|}{ Readmitted to the ICU within $7 \mathrm{~d}$} & \multirow{3}{*}{$P$} & \multirow{3}{*}{ Adj. OR } & \multirow{3}{*}{$95 \% \mathrm{CI}$} & \multirow{3}{*}{$P$} \\
\hline & & & \multicolumn{2}{|c|}{ No $(n=628,795)$} & \multicolumn{2}{|c|}{ Yes $(n=29,657)$} & & & & \\
\hline & $n$ & $\%$ & $n$ & $\%$ & $n$ & $\%$ & & & & \\
\hline Sex & & & & & & & $<.001$ & & & \\
\hline Female & 244,241 & 37.09 & 233,736 & 37.17 & 10,505 & 35.42 & & 1 & & \\
\hline Male & 414,211 & 62.91 & 395,059 & 62.83 & 19,152 & 64.58 & & 1.16 & $1.13-1.19$ & $<.001$ \\
\hline Age & & & & & & & $<.001$ & & & \\
\hline $17-44 \mathrm{y}$ & 78,830 & 11.97 & 77,305 & 12.29 & 1,525 & 5.14 & & 1 & & \\
\hline $45-54 y$ & 79,043 & 12.00 & 77,119 & 12.26 & 1,924 & 6.49 & & 1.10 & $1.02-1.19$ & .01 \\
\hline $55-64$ y & 98,169 & 14.91 & 94,820 & 15.08 & 3,349 & 11.29 & & 1.36 & $1.27-1.46$ & $<.001$ \\
\hline $65-74$ y & 140,524 & 21.34 & 134,136 & 21.33 & 6,388 & 21.54 & & 1.51 & $1.41-1.61$ & $<.001$ \\
\hline$\geq 75 \mathrm{y}$ & 261,886 & 39.77 & 245,415 & 39.03 & 16,471 & 55.54 & & 1.66 & $1.56-1.76$ & $<.001$ \\
\hline Monthly salary & & & & & & & $<.001$ & & & \\
\hline LIH & 20,426 & 3.17 & 19,286 & 3.13 & 1,140 & 4.15 & & 1 & & \\
\hline$\leq \mathrm{NT} \$ 17,880$ & 33,148 & 5.15 & 32,009 & 5.20 & 1,139 & 4.14 & & 0.98 & $0.90-1.08$ & .71 \\
\hline NT $\$ 17,881-22,800$ & 270,623 & 42.05 & 258,836 & 42.01 & 11,787 & 42.88 & & 0.90 & $0.84-0.97$ & .004 \\
\hline NT\$22,801-28,800 & 173,771 & 27.00 & 165,844 & 26.92 & 7,927 & 28.83 & & 0.94 & $0.87-1.01$ & .10 \\
\hline NT\$28,801-36,300 & 60,028 & 9.33 & 57,415 & 9.32 & 2,613 & 9.50 & & 0.94 & $0.86-1.02$ & .11 \\
\hline NT\$36,301-45,800 & 39,129 & 6.08 & 37,910 & 6.15 & 1,219 & 4.43 & & 0.83 & $0.76-0.91$ & $<.001$ \\
\hline NT\$45,801-57,800 & 17,398 & 2.70 & 16,793 & 2.73 & 605 & 2.20 & & 0.88 & $0.78-0.98$ & .02 \\
\hline$>\mathrm{NT} \$ 57,800$ & 29,069 & 4.52 & 28,008 & 4.55 & 1,061 & 3.86 & & 0.86 & $0.78-0.94$ & .002 \\
\hline Degree of urbanization & & & & & & & $<.001$ & & & \\
\hline Level 1 & 153,617 & 23.74 & 147,660 & 23.89 & 5,957 & 20.45 & & 1 & & \\
\hline Level 2 & 179,749 & 27.77 & 171,929 & 27.82 & 7,820 & 26.84 & & 1.06 & $1.02-1.10$ & .007 \\
\hline Level 3-4 & 217,404 & 33.59 & 207,031 & 33.50 & 10,373 & 35.61 & & 1.06 & $1.01-1.10$ & .008 \\
\hline Level 5-7 & 96,430 & 14.90 & 91,448 & 14.80 & 4,982 & 17.10 & & 1.10 & $1.05-1.16$ & $<.001$ \\
\hline CCI score & & & & & & & $<.001$ & & & \\
\hline 0 & 103,063 & 15.65 & 100,361 & 15.96 & 2,702 & 9.11 & & 1 & & \\
\hline 1 & 116,723 & 17.73 & 111,836 & 17.79 & 4,887 & 16.48 & & 1.16 & $1.09-1.22$ & $<.001$ \\
\hline 2 & 123,350 & 18.73 & 117,750 & 18.73 & 5,600 & 18.88 & & 1.20 & $1.14-1.27$ & $<.001$ \\
\hline $3-4$ & 154,725 & 23.50 & 146,478 & 23.30 & 8,247 & 27.81 & & 1.28 & $1.21-1.34$ & $<.001$ \\
\hline$\geq 5$ & 160,591 & 24.39 & 152,370 & 24.23 & 8,221 & 27.72 & & 1.41 & $1.34-1.48$ & $<.001$ \\
\hline \multicolumn{11}{|l|}{ Complications } \\
\hline Laryngeal edema & & & & & & & .37 & & & \\
\hline No & 657,550 & 99.86 & 627,928 & 99.86 & 29,622 & 99.88 & & 1 & & \\
\hline Yes & 902 & 0.14 & 867 & 0.14 & 35 & 0.12 & & 1.11 & $0.78-1.57$ & .57 \\
\hline Pneumothorax & & & & & & & $<.001$ & & & \\
\hline No & 643,217 & 97.69 & 614,726 & 97.76 & 28,491 & 96.07 & & 1 & & \\
\hline Yes & 15,235 & 2.31 & 14,069 & 2.24 & 1,166 & 3.93 & & 1.59 & $1.48-1.70$ & $<.001$ \\
\hline Subcutaneous emphysema & & & & & & & .14 & & & \\
\hline No & 657,900 & 99.92 & 628,275 & 99.92 & 29,625 & 99.89 & & 1 & & \\
\hline Yes & 552 & 0.08 & 520 & 0.08 & 32 & 0.11 & & 1.83 & $1.28-2.63$ & .001 \\
\hline Pneumonia & & & & & & & $<.001$ & & & \\
\hline No & 349,352 & 53.06 & 340,958 & 54.22 & 8,394 & 28.30 & & 1 & & \\
\hline Yes & 309,100 & 46.94 & 287,837 & 45.78 & 21,263 & 71.70 & & 2.07 & $2.01-2.14$ & $<.001$ \\
\hline Oxygen toxicity & & & & & & & .008 & & & \\
\hline No & 658,392 & 99.99 & 628,742 & 99.99 & 29,650 & 99.98 & & 1 & & \\
\hline Yes & 60 & 0.01 & 53 & 0.01 & 7 & 0.02 & & 4.85 & $2.02-11.62$ & $<.001$ \\
\hline Pulmonary embolism & & & & & & & .08 & & & \\
\hline No & 653,950 & 99.32 & 624,520 & 99.32 & 29,430 & 99.23 & & 1 & & \\
\hline Yes & 4,502 & 0.68 & 4,275 & 0.68 & 227 & 0.77 & & 1.25 & $1.08-1.45$ & .003 \\
\hline Pulmonary edema & & & & & & & $<.001$ & & & \\
\hline No & 635,119 & 96.46 & 606,791 & 96.50 & 28,328 & 95.52 & & 1 & & \\
\hline Yes & 23,333 & 3.54 & 22,004 & 3.50 & 1,329 & 4.48 & & 1.26 & $1.19-1.35$ & $<.001$ \\
\hline
\end{tabular}


Table 3. Continued

\begin{tabular}{|c|c|c|c|c|c|c|c|c|c|c|}
\hline \multirow{3}{*}{ Variables } & \multirow{2}{*}{\multicolumn{2}{|c|}{$\begin{array}{c}\text { Total } \\
(N=658,452)\end{array}$}} & \multicolumn{4}{|c|}{ Readmitted to the ICU within $7 \mathrm{~d}$} & \multirow{3}{*}{$P$} & \multirow{3}{*}{ Adj. OR } & \multirow{3}{*}{$95 \% \mathrm{CI}$} & \multirow{3}{*}{$P$} \\
\hline & & & \multicolumn{2}{|c|}{ No $(n=628,795)$} & \multicolumn{2}{|c|}{ Yes $(n=29,657)$} & & & & \\
\hline & $n$ & $\%$ & $n$ & $\%$ & $n$ & $\%$ & & & & \\
\hline Hospital accreditation level (ICU) & & & & & & & $<.001$ & & & \\
\hline $\mathrm{MC}$ & 292,779 & 44.46 & 284,008 & 45.17 & 8,771 & 29.57 & & 1 & & \\
\hline $\mathrm{RH}$ & 312,170 & 47.41 & 297,198 & 47.26 & 14,972 & 50.48 & & 1.45 & $1.4-1.49$ & $<.001$ \\
\hline $\mathrm{DH}$ & 53,503 & 8.13 & 47,589 & 7.57 & 5,914 & 19.94 & & 2.65 & $2.53-2.77$ & $<.001$ \\
\hline Hospital ownership (ICU) & & & & & & & $<.001$ & & & \\
\hline Public & 202,272 & 30.72 & 193,537 & 30.78 & 8,735 & 29.45 & & 1 & & \\
\hline Private & 456,180 & 69.28 & 435,258 & 69.22 & 20,922 & 70.55 & & 0.88 & $0.79-0.97$ & .01 \\
\hline Hospital ownership (extended-care facility) & & & & & & & $<.001$ & & & \\
\hline Public & 199,657 & 30.32 & 191,426 & 30.44 & 8,231 & 27.75 & & 1 & & \\
\hline Private & 458,795 & 69.68 & 437,369 & 69.56 & 21,426 & 72.25 & & 1.17 & $1.06-1.30$ & .003 \\
\hline Type of extended-care facility & & & & & & $<.001$ & & & & \\
\hline $\mathrm{GW}$ & 595,568 & 90.45 & 575,810 & 91.57 & 19,758 & 66.62 & & 1 & & \\
\hline $\mathrm{RCC}$ & 46,980 & 7.13 & 40,676 & 6.47 & 6,304 & 21.26 & & 3.45 & $3.32-3.59$ & $<.001$ \\
\hline $\mathrm{RCW}$ & 15,522 & 2.36 & 11,947 & 1.90 & 3,575 & 12.05 & & 4.26 & $4.01-4.52$ & $<.001$ \\
\hline HRC & 382 & 0.06 & 362 & 0.06 & 20 & 0.07 & & 1.08 & $0.64-1.81$ & .78 \\
\hline ICU length of stay & & & & & & & $<.001$ & & & \\
\hline$<21 \mathrm{~d}$ & 571,746 & 86.83 & 550,232 & 87.51 & 21,514 & 72.54 & & 1 & & \\
\hline$=21 \mathrm{~d}$ & 13,035 & 1.98 & 11,768 & 1.87 & 1,267 & 4.27 & & 1.19 & $1.10-1.28$ & $<.001$ \\
\hline$>21 \mathrm{~d}$ & 73,671 & 11.19 & 66,795 & 10.62 & 6,876 & 23.19 & & 1.51 & $1.45-1.56$ & $<.001$ \\
\hline $\begin{array}{l}\text { Adj. OR = adjusted odds ratio } \\
\text { LIH = low-income household } \\
\text { NT\$ = New Taiwan dollar } \\
\text { CCI = Charlson comorbidity index } \\
\text { MC = medical center } \\
\text { RH = regional hospital } \\
\text { DH = district hospital } \\
\text { GW = general ward } \\
\text { RCC = respiratory care center } \\
\text { RCW = respiratory care ward } \\
\text { HRC = home respiratory care }\end{array}$ & & & & & & & & & & \\
\hline
\end{tabular}

wards, followed by the respiratory care centers, which showed a risk of readmission 3.45 times that of the general wards. The private hospitals exhibited a higher rate of readmission than did the public hospitals $(\mathrm{OR}=1.17$; Table 3).

\section{Discussion}

\section{Rate of Readmission}

Previous studies have shown that decisions on subject transfers from the ICU were influenced by factors such as a reduction in subject care or the required bed turnover rate. ${ }^{13-15}$ Subjects being transferred from the ICU prematurely or having severe conditions during the transfer were factors that increased the rate of readmission. ${ }^{16,17}$ However, subjects did not benefit from delayed transfers if their conditions were stable because it increased their medical expenses. ${ }^{10,18,19}$
Results on the rate of readmission within $7 \mathrm{~d}$ after ICU step-down reported in previous studies were $5.2 \%,{ }^{15}$ $28.7 \%,{ }^{20}$ and $8.1 \%{ }^{21}$ in Canada (2009), the United Kingdom (2010), and the United States (2005), respectively. In the present study, the rate of readmission within $7 \mathrm{~d}$ after step-down for mechanical ventilation subjects was $4.5 \%$. Compared with the United States and Canada, the managed care method for strengthening management models applied by the National Health Insurance Administration, Ministry of Health and Welfare, has achieved the expected medical quality improvements.

\section{Influence of Health Status on Readmission}

According to a review of 35 evidence-based medical studies, Elliot et $\mathrm{al}^{22}$ found that subjects readmitted to the ICU were generally older, diagnosed with more comorbidities, showed higher disease severity, and previously stayed at the ICU longer compared with other subjects. 
Taiwanese scholars Lai et al ${ }^{23}$ analyzed all resident ICU subjects in 2006 from the National Health Insurance Research Database and determined that readmission-related factors included age ( $>39 \mathrm{y}$ ), lung-related disorders, pneumonia, septicemia, and chronic obstructive pulmonary disease. The present study determined that readmission to the ICU was associated with risk factors such as old age, severe comorbidities, and long previous stay in the ICU (all equally significant; Table 3 ). Regarding severity of comorbidity, this study used the National Health Insurance Research Database in a retrospective study, which was conducted using only the Charlson comorbidity index and not the widespread clinical application of the APACHE (Acute Physiology and Chronic Health Evaluation) II for measuring the disease severity. ${ }^{12}$ These measurements yielded outcomes similar to those reported in other studies that have applied the APACHE II system. The outcomes indicated that high disease severities yielded high risks of readmission. ${ }^{16,24-28}$

\section{Diagnoses for ICU Readmissions}

Rosenberg et al indicated that primary diagnoses of subjects who were readmitted to the ICU consisted of pneumonia, respiratory failure, and septicemia. ${ }^{29}$ Reports from South Korea attributed common causes of ICU readmission to problems such as respiratory diseases, postoperative complications, and septicemia. ${ }^{30}$ Conditions similar to these were observed in the readmitted subjects in this study. The present study focused on mechanically ventilated subjects who were originally diagnosed with respiratory failure. Inappropriate cleaning and maintenance of the artificial airways of mechanically ventilated subjects tends to result in pneumonia, which subsequently causes septicemia. Consequently, the subjects must be readmitted to the ICU.

This study revealed that $64.77 \%$ of the subjects who were readmitted to the ICU within $7 \mathrm{~d}$ after step-down had primary diagnoses similar to those obtained during their previous ICU residency. This rate was comparatively higher than those reported in other published papers $\left(19 \%{ }^{31}\right.$ and $60 \%{ }^{32}$ ). The subjects of this study continued using ventilators from step-down to readmission. In addition, factors such as the severity-based cost declaration system of the National Health Insurance and the deterioration of the mechanical ventilation subjects are conditions for ICU readmission. Thus, whether these conditions affect proper clinical diagnostic corrections performed by physicians has yet to be investigated.

\section{Influence of Length of Stay in the ICU}

The managed care method proposed by the National Health Insurance Administration, Ministry of Health and Welfare for ventilator-dependent subjects limited the ICU care stages to $21 \mathrm{~d}$. Thus, this study investigated whether these subjects were forced to leave on day 21 of ICU residency because of the stay effect. The results showed that the subjects who were discharged to a lower level of care within $21 \mathrm{~d}$ of ICU residency exhibited the lowest rate of readmission $(3.76 \%)$; however, the risks of readmission for subjects who were stepped down on or after day 21 were both higher than those for subjects who stepped down before day 21 of ICU residency (Table 3). Thus, whether subjects are forced to leave on day 21 has yet to be determined. Previous studies have indicated that the factors causing subject readmission may be related to the care standards of the extended-care units. ${ }^{22}$

\section{Influence of Extended-Care Facility Type on ICU Readmissions}

The results showed that the extended-care facility types (general wards, respiratory care centers, respiratory care wards, and home respiratory cares) influenced the subjects' risk of ICU readmission within $7 \mathrm{~d}$ after step-down $(P<.05)$ (Table 3). Among the variables, the respiratory care wards showed the highest rate $(23.03 \%)$ and risk $(\mathrm{OR}=4.26)$ of readmission, followed by the respiratory care centers (rate of readmission $=13.42 \%$; $\mathrm{OR}=3.45$ ). In contrast to Kramer's study (in the United States), the subjects displayed a $6.9 \%$ rate of readmission after stepping down to extended-care facilities. ${ }^{33}$ Care standards of the extended-care facilities have yet to be discussed in detail. In addition, the National Health Insurance Administration, Ministry of Health and Welfare, used respiratory care centers as a safeguard for weaning subjects off ventilators; however, $1.9 \%$ of the subjects were still stepped down directly to respiratory care wards. Consequently, this resulted in a $23.03 \%$ rate of readmission, and process control for subject step-down transfers has yet to be reinforced.

\section{Influence of Hospital Levels and Ownership on Readmissions}

Table 3 shows that the variables of hospital levels and ownership influenced the subjects' risk of ICU readmission within $7 \mathrm{~d}$ after step-down $(P<.05)$. This study indicated that low hospital levels yielded high rates and risks of readmission because human resource allocations for subject care are comparatively low in low-level hospitals. Consequently, care quality cannot match that required in high-level hospitals, and similar results were obtained in Kramer's American study. ${ }^{33}$ Regarding the ownership of ICU hospitals, the number of readmitted subjects $(20,922)$ and rate of readmission $(4.59 \%)$ were both higher in private hospitals than those in public hospitals. However, after controlling for subject characteristics and severity of conditions, private hospitals yielded 
comparatively lower risks of readmission $(\mathrm{OR}=0.88$, $P<.05)$. This may have been because private hospitals are more careful with regard to releasing subjects from the ICUs; however, detailed causes have yet to be investigated. Regarding ownership of extended-care facilities, private hospitals featured the highest number of readmitted subjects $(21,462)$ as well as rate and risk of readmission $(4.67 \%$; OR $=1.17)$, and the results were statistically significant $(P<.05)$. Thus, the care quality of extendedcare facilities of private hospitals must be further investigated.

\section{Research Limitations}

This study adopted a secondary database for analysis. This database primarily contained cost declaration data and can thus be used to determine only the conditions of medical applications and resource consumption; it does not contain subjects' clinical data, such as the APACHE II diagnostic codes and scores. Thus, this study can only speculate about subjects' disease severity by using the Charlson comorbidity index. Clinical records must be accessed and reviewed for confirmation. Moreover, this study obtained only the current residency primary diagnosis of subjects but not their disease diagnosis during ICU residency. Thus, the actual causes of readmission after ICU step-down, such as the deterioration of diseases or the formation of complications or new comorbidities, could not be determined.

\section{Conclusion}

The readmission of the mechanical ventilation subjects (who were at least $17 \mathrm{y}$ old) within $7 \mathrm{~d}$ after ICU stepdown transfers was influenced by the variables of subject demographics, health status, ICU hospital characteristics, extended-care facility characteristics, and stay in the ICU. Based on the results of this study, the male and older subjects, subjects with severe diseases, subjects in lowlevel ICU hospitals, subjects who out-transferred after day 21 of ICU residency, and subjects who were stepped down to respiratory care wards exhibited relatively high readmission risks.

\section{REFERENCES}

1. Berthelsen PG, Cronqvist M. The first intensive care unit in the world: Copenhagen 1953. Acta Anaesthesiol Scand 2003;47(10): 1190-1195.

2. Reisner-Sénélar $\mathrm{L}$. The birth of intensive care medicine: Bjorn Ibsen's records. Intensive Care Med 2011;37(7):1084-1086.

3. Berenson RA. Intensive Care Units (ICUs): Clinical Outcomes, Costs, and Decisionmaking (Health Technology Case Study 28). Washington, DC: Office of Technology Assessment, U.S. Congress, OTAHCS-28;1984.
4. Halpern NA, Pastores SM, Greenstein RJ. Critical care medicine in the United States 1985-2000: an analysis of bed numbers, use, and costs. Crit Care Med 2004;32(6):1254-1259.

5. Halpern NA, Pastores SM. Critical care medicine in the United States 2000-2005: an analysis of bed numbers, occupancy rates, payer mix, and costs. Crit Care Med 2010;38(1):65-71.

6. The Ministry of Health and Welfare of the Republic of China. Improved emergency and critical care hospital medical plan in 1998 (Chinese). http://www.24drs.com/daily/article.asp?x_no $=2708$

7. National Health Insurance announced, Integrated prospective payment program for prolonged mechanical ventilation subjects in 2000 . (Chinese). The Department of Health Gazette 2000;29(23):21-26.

8. Carson SS. Outcomes of prolonged mechanical ventilation. Curr Opin Crit Care 2006;12(5):405-411.

9. Hung MC, Lu HM, Chen L, Lin MS, Chen CR, Yu CJ, Wang JD. Cost per QALY (quality-adjusted life year) and lifetime cost of prolonged mechanical ventilation in Taiwan. PLoS One 2012;7(9): e44043. doi: 10.1371/journal.pone.0044043.

10. Liu CJ, Chu CC, Chen W, Cheng WE, Shih CM, Tsai YS, et al Impact of Taiwan's integrated prospective payment program on prolonged mechanical ventilation: a 6-year nationwide study. Respir Care 2013;58(4):676-682.

11. Liu CY, Hung YT, Chuang YL, Chen YJ, Weng WS, Liu JS, Liang KY. Incorporating development stratification of Taiwan townships into sampling design of large scale health interview survey. J Health Manage 2006;4(1):1-22.

12. Deyo RA, Cherkin DC, Ciol MA. Adapting a clinical comorbidity index for use with ICD-9-CM administrative databases. J Clin Epidemiol 1992;45(6):613-619.

13. Goldfrad C, Rowan K. Consequences of discharges from intensive care at night. Lancet 2000;355(9210):1138-1242.

14. Beck DH, McQuillan P, Smith GB. Waiting for the break of dawn? The effects of discharge time, discharge TISS scores and discharge facility on hospital mortality after intensive care. Intensive Care Med 2002;28(9):1287-1293.

15. Chrusch CA, Olafson KP, McMillan PM, Roberts DE, Gray PR. High occupancy increases the risk of early death or readmission after transfer from intensive care. Crit Care Med 2009;37(10): 2753-2758

16. Durbin CG Jr, Kopel RF. A case-control study of subjects readmitted to the intensive care unit. Crit Care Med 1993;21(10):1547-1553.

17. Utzolino S, Kaffarnik M, Keck T, Berlet M, Hopt UT. Unplanned discharges from a surgical intensive care unit: readmissions and mortality. J Crit Care 2010;25(3):375-381.

18. Metnitz PG, Fieux F, Jordan B, Lang T, Moreno R, Le Gall JR. Critically ill subjects readmitted to intensive care units: lessons to learn? Intensive Care Med 2003;29(2):241-248.

19. Knaus WA, Wagner DP, Zimmerman JE, Draper EA. Variations in mortality and length of stay in intensive care units. Ann Intern Med 1993;118(10):753-761.

20. Miller CE, Chana A, Matejowsky C, Welch JR, Breen P. Critical care readmissions: the clinical and organisational costs. Electronic Poster presented at the European Society of Intensive Care Medicine Congress, held October 9-13, 2010, in Barcelona, Spain, (abstr 0304). http://posterconsultation.esicm.org/ModuleConsultationPoster/posterDetail.aspx?int IdPoster=1473. Accessed August 6, 2015.

21. Gajic O, Malinchoc M, Comfere TB, Harris MR, Achouiti A, Yilmaz $\mathrm{M}$, et al. The stability and workload index for transfer score predicts unplanned intensive care unit subject readmission: initial development and validation. Crit Care Med 2008;36(3):676-682.

22. Elliott M, Worrall-Carter L, Page K. Intensive care readmission: a contemporary review of the literature. Intensive Crit Care Nurs 2014; 30(3):121-137. 


\section{Risk Factors for ICU Readmission in Mechanically Ventilated Subjects}

23. Lai JI, Lin HY, Lai YC, Lin PC, Chang SC, Tang GJ. Readmission to the intensive care unit: a population-based approach. J Formos Med Assoc 2012;111(9):504-509.

24. Chen LM, Martin CM, Keenan SP, Sibbald WJ. Subjects readmitted to the intensive care unit during the same hospitalization: clinical features and outcomes. Crit Care Med 1998;26(11):18341841.

25. Chung DA, Sharples LD, Nashef SA. A case-control analysis of readmissions to the cardiac surgical intensive care unit. Eur J Cardiothorac Surg 2002;22(2):282-286.

26. Ho KM, Dobb GJ, Lee KY, Finn J, Knuiman M, Webb SA. The effect of comorbidities on risk of intensive care readmission during the same hospitalization: a linked data cohort study. J Crit Care 2009;24(1):101-107.

27. Conlon N, O'Brien B, Herbison GP, Marsh B. Long-term functional outcome and performance status after intensive care unit re-admission: a prospective survey. Br J Anaesth 2008;100(2): 219-223.
28. Kramer AA, Higgins TL, Zimmerman JE. Intensive care unit readmissions in U.S. hospitals: subject characteristics, risk factors, and outcomes. Crit Care Med 2012;40(1):3-10.

29. Rosenberg AL, Hofer TP, Hayward RA, Strachan C, Watts CM. Who bounces back? Physiologic and other predictors of intensive care unit readmission. Crit Care Med 2001;29(3):511-518.

30. Yoon KB, Koh SO, Han DW, Kang OC. Discharge decision-making by intensivists on readmission to the intensive care unit. Yonsei Med J 2004;45(2):193-198.

31. Cooper GS, Sirio CA, Rotondi AJ, Shepardson LB, Rosenthal GE. Are readmissions to the intensive care unit a useful measure of hospital performance? Med Care 1999;37(4):399-408.

32. Kirby EG, Durbin CG. Establishment of a respiratory assessment team is associated with decreased mortality in subjects re-admitted to the ICU. Respir Care 1996;41(5):903-907.

33. Kramer AA, Higgins TL, Zimmerman JE. The association between ICU readmission rate and subject outcomes. Crit Care Med 2013; 41(1):24-33. 